\title{
Analysis of the Influence of Laser Power on the Microstructure and Properties of a Titanium Alloy-Reinforced Boron Carbide Matrix Composite (Ti6Al4V-B $\left.{ }_{4} \mathrm{C}\right)$
}

\author{
Musibau O. Ogunlana* - Esther T. Akinlabi - Mutiu F. Erinosho \\ University of Johannesburg, Department of Mechanical Engineering Science, South Africa
}

\begin{abstract}
Laser Metal Deposition (LMD) process is a means of producing metal composites with the aid of a laser beam, ejected onto the substrate with the participating powder and fused together after solidification. In this research work, Ti6Al4V alloy is fused with 20 wt $\%$ of $B_{4} C$ in order to form metal matrix composites (MMCs). Using the Ytterbium Fibre Laser System powdered at $3000 \mathrm{~W}$, the laser powers were varied between $800 \mathrm{~W}$ and $2400 \mathrm{~W}$ while all other supporting process parameters were kept constant. The deposited Ti6Al4V-B ${ }_{4} \mathrm{C}$ composites were characterized through the surfacing microstructure, microhardness and dry sliding wear. The microstructural properties of the deposited samples were profound, with a Widmanstätten structure of $\alpha$-Ti, $\beta$-Ti and $(\alpha+\beta)$ Ti phases. The microhardness tests revealed that the composites deposited with a laser power of $2000 \mathrm{~W}$ exhibited the highest hardness value and standard deviation of HV $445 \pm 61$. Furthermore, characterisation revealed that the sample produced with the laser power of $800 \mathrm{~W}$ had the lowest wear loss and wear rate of $35.2 \times 10^{-3} \mathrm{~mm}^{3}$ and $6.42 \times 10^{-4} \mathrm{~mm}^{3} / \mathrm{Nm}$. However, the motivation for this work is to improve the material properties of the Ti6Al4V alloy for surface engineering applications.
\end{abstract}

Keywords: Dry sliding wear, LMD, microhardness, microstructure, Ti6AI4V-B $\mathrm{B}_{4} \mathrm{C}$ composites, X-Ray Diffraction

Highlights

- $\quad$ The presence of $\mathrm{TiB}$ and $\mathrm{TiB}_{2}$ compounds was detected between the interface of the Ti6Al4V- $\mathrm{B}_{4} \mathrm{C}$ composite and substrate.

- $\quad$ The microstructures were mostly characterised with Widmanstätten structures of $\alpha$-Ti, $\beta$-Ti and $(\alpha+\beta)$ Ti phases.

- $\quad$ The wear loss and wear rate of $35.2 \times 10^{-3} \mathrm{~mm}^{3}$ and $6.42 \times 10^{-4} \mathrm{~mm}^{3} / \mathrm{Nm}$ were achieved.

- The optimized process parameters were established between the laser power of $2000 \mathrm{~W}$ and $2400 \mathrm{~W}$ due to the defect-free deposition output.

\section{INTRODUCTION}

Titanium and its alloys are used for highly demanding applications, such as in the fabrication of some of the most critical and highly stressed civilian and military aircraft parts, chemical processing, automobile industries, nuclear power plants, food processing plants and oil refinery heat exchangers. This wide range of applications has been attributed to its excellent properties, such as low density, high specific strength, heat resistance, corrosion resistance, low temperature resistance, and excellent biocompatibility. Several suggestions have been made that the physical and mechanical properties of titanium can be improved through the integration of reinforcing compounds using the principle of metal matrix composites (MMCs), since they combine the properties of ceramics and metals to produce good shear strength, high temperature strength and elevated hardness composites [1]. Titanium carbide has been agglomerated with Ti6Al4V alloy to improve its wear properties [2]. Different coatings such as plasmasprayed Al-bronze have been applied to the surface of titanium to improve the operational life [3]. The microstructural behaviour of titanium alloy is an important aspect to be studied with the establishment of new phases [4].

In contrast, laser metal deposition (LMD) is an additive manufacturing (AM) technique that serves as a recommended technique for processing titanium and its alloy, since it addresses most of the problems of the traditional manufacturing methods [5]. This AM technology is also a promising aerospace manufacturing technique due to its potential of reducing the buy-to-fly ratio and repairing high valued parts [6]. Among the various methods of coating the surface of materials, which includes chemical vapour deposition, physical vapour deposition, spraying, etc., the LMD process is believed to have a greater advantage over other methods of coating [7]. Some of the advantages of using the LMD process include the ability to produce parts directly from a 3-dimensional computer aided design (CAD) model of the part [8] with the required surface coating in one step [9]; and its ability to be used for repair of existing worn out parts that were not repairable in the past [10]. Despite the significant progress in this field, there are still some of technical challenges that need improvement, which includes material characterization and availability [11]. The adopted approach of layer-by- 
layer of building a component has been attributed to the laser powder deposition technique. However, homogeneous structure, production of complex geometries and improved mechanical properties are the possible features attributed to the CAD systems [12]. In the same vein, complex parts can be produced as one single component through the LMD process, without requiring later assembly [13].

The mechanical properties of titanium carbide and titanium alloy (TiC/Ti6Al4V) composites were improved with the addition of different percentages of boron. However, the refinement mechanism of boron was ascribed to the combined effects of the nucleation growth at the super-cooled zone [14]. In addition, this $\mathrm{TiC}$ is regarded as the refractory ceramic material that has been widely used to improve the mechanical properties of titanium and its alloy. The thermal oxidation treatment carried out on Ti6Al4V/10 vol.\% TiC composites have significantly improved its wear resistance properties due to the formation of hard oxide layer [15]. A different approach can also be used for the deposition process such as the direct laser fabrication techniques and still give good bonding [16], or by using a vacuum induction melting furnace for the fabrication process [17]. Thus, generally, laser material processing has developed a significant advantage in the field of engineering [18].

Furthermore, research has been conducted on laser surface re-melting, laser alloying, and laser cladding to improve the surface properties of many kinds of metals. It is noteworthy that the coatings formed by laser cladding process show dense microstructures and exhibit strong metallurgical bonding with the associated substrate [19], and these would always be achieved if the process parameters employed are well understood. However, the clad width, height, and geometry need to be put in place for complete deposition [20].

In the group of the most important nonmetallic hard materials, boron carbide, $\mathrm{B}_{4} \mathrm{C}$ has played a role in the MMC of the primary alloy. It is currently used in high-technology industries fastbreeders, lightweight armours and high-temperature thermoelectric conversion due to such properties as high melting point, outstanding hardness, good mechanical properties, low specific weight and great resistance to chemical agents [21]. It is an extremely promising material for a variety of applications that require elevated hardness, good wear and corrosion resistance [22] and [23], and the highlighted areas of application are due to its excellent properties [24]. $\mathrm{B}_{4} \mathrm{C}$ also finds application in the nuclear industry and high-temperature thermo-electric conversion, but there is a restriction to its wide industrial application because of low strength (about $200 \mathrm{MPa}$ to $400 \mathrm{MPa}$ ), low fracture toughness $\left(2 \mathrm{MPa} / \sqrt{ }_{\mathrm{m}}\right.$ to $\left.3 \mathrm{MPa} /{ }^{\mathrm{m}}\right)$, as well as poor sinterability that results from its low selfdiffusion coefficient.

Grain-refined boron-modified Ti6A14V alloy has shown significant improvement in strength, stiffness, fatigue resistance and fracture toughness when fused together. However, the enhanced formability of the boron-modified alloy during large deformation without cracking as opposed to the normal alloy was reviewed. The microstructural evolutions of the specimen during the hot deformation were also revealed to have significant influence on the mechanical properties of the final product. However, the understanding of the processing-microstructural relationship during the thermo-mechanical processing of boron-modified Ti6Al4V alloy was discovered to be of great significant [25] and [26]. The failures of materials vary, and it is more noticeable in complex laminates and composites than in the homogeneous materials [27].

The wear properties of laser-deposited titanium boride-and carbide-reinforced composite were investigated. Excellent abrasive and adhesive wear resistance under sliding wear test conditions were achieved. In addition, the strength and hardness of the surface of samples were significantly enhanced by the in situ formed compounds [28]. Premixed titanium and boron were concocted in the weight ratio of $8: 1$ with a sodium silicate solution. The mixtures were laser deposited onto a clean Ti6Al4V alloy substrate. Hard ceramic compounds of $\mathrm{TiB}$ and $\mathrm{TiB}_{2}$ were formed in the deposited composite. In addition, the excellent wear resistance of the laser-deposited samples was also discerned. However, it was finally reported that the load-bearing capability of the substrate has a strong support for the deposit [29].

Despite the fascinating properties Ti6Al4V alloy has, its wear resistance properties need to be improved. This poor wear characteristic of the alloy has inspired the addition of 20 weight per cent (wt \%) of $\mathrm{B}_{4} \mathrm{C}$ to upgrade its wear resistance. The laser powers were varied between $800 \mathrm{~W}$ and $2400 \mathrm{~W}$ respectively while keeping the scanning speed, the powder flow rate and gas flow rate constant throughout the experiments. The microstructures, the microhardness as well as the wear properties of the laser deposited Ti6Al4V-B ${ }_{4} \mathrm{C}$ have been characterized. 


\section{EXPERIMENTAL PROCEDURE}

The LMD process was achieved with a $3.0 \mathrm{~kW}$ Ytterbium fibre laser system at the Council for Scientific and Industrial Research, (CSIR), South Africa. A Kuka robot attached with a nozzle are used to carry out the deposition process. A rectangular Ti6Al4V alloy substrate block with dimensions of 102 $\mathrm{mm} \times 102 \mathrm{~mm} \times 7 \mathrm{~mm}$ is prepared for the LMD of the Ti6Al4V-B ${ }_{4} \mathrm{C}$. The substrate was sandblasted and cleaned under tap water prior to the LMD coating. The Kuka robot and the powder feeder are in connection with the laser system. The powder feeder has two cylindrical glass jars (hopper) where the powders are kept. A three-way nozzle is attached to the end of the Kuka arm. It is through the nozzle that the powders and the laser beam were ejected onto the substrate. The powders are sucked (with aid of gas) into the nozzle passing through hose connections; and were delivered into the melt pool that was created by the laser beam. Ti6Al4V alloy and $\mathrm{B}_{4} \mathrm{C}$ powders are the two powders used for the experiment. Both powders were supplied by the Alfa Aesar Company in Germany. The particle size of the boron carbide powder is between $22 \mu \mathrm{m}$ to $59 \mu \mathrm{m}$, while the titanium alloy powder's particle size ranges between $45 \mu \mathrm{m}$ to $90 \mu \mathrm{m}$. Fig. 1 shows the scanning electron microscope (SEM) morphology and the energy dispersion spectroscopy (EDS) analysis of the Ti6Al4V alloy and $\mathrm{B}_{4} \mathrm{C}$ powders.
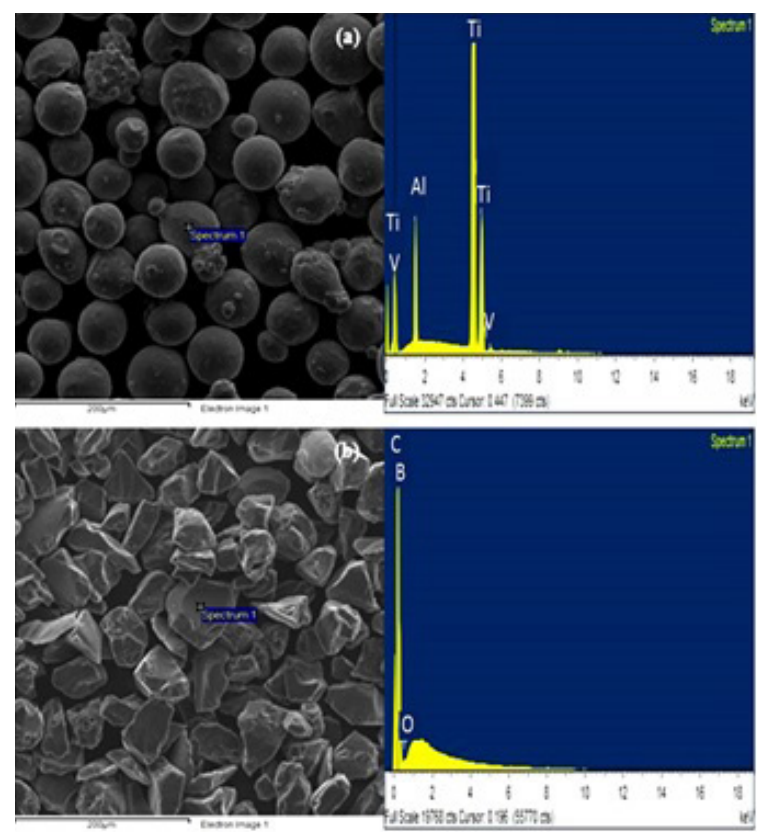

Fig. 1. SEM morphology and EDS analysis; a) Ti6Al4V powder; and b) $B_{4} C$ powder
The SEM morphologies of the Ti6Al4V powder are spherical with dissimilar sizes. The major peak observed in the spectrum is Ti. The SEM morphologies of the $\mathrm{B}_{4} \mathrm{C}$ powder appear amorphous and inform of stone pebbles. The major peaks observed in the $\mathrm{B}_{4} \mathrm{C}$ spectrum are boron (B) and carbide (C). Table 1 shows the experimental matrix used for the deposition of the Ti6Al4V-B ${ }_{4} \mathrm{C}$ composite.

Table 1. Experimental matrix

\begin{tabular}{ccccc}
\hline \multirow{2}{*}{$\begin{array}{c}\text { Sample } \\
\text { name }\end{array}$} & $\begin{array}{c}\text { Laser power } \\
{[\mathrm{W}]}\end{array}$ & $\begin{array}{c}\text { Scanning } \\
\text { speed }[\mathrm{m} / \mathrm{min}]\end{array}$ & \multicolumn{2}{c}{ Powder flow rate [rpm] } \\
\cline { 5 - 5 } S1 & 800 & 1.0 & Ti6Al4V & $\mathrm{B}_{4} \mathrm{C}$ \\
\hline $\mathrm{S} 2$ & 1000 & 1.0 & 3.2 & 0.8 \\
\hline $\mathrm{S} 3$ & 1200 & 1.0 & 3.2 & 0.8 \\
\hline $\mathrm{S} 4$ & 1400 & 1.0 & 3.2 & 0.8 \\
\hline S5 & 1600 & 1.0 & 3.2 & 0.8 \\
\hline S6 & 1800 & 1.0 & 3.2 & 0.8 \\
\hline S7 & 2000 & 1.0 & 3.2 & 0.8 \\
\hline S8 & 2200 & 1.0 & 3.2 & 0.8 \\
\hline S9 & 2400 & 1.0 & 3.2 & 0.8 \\
\hline
\end{tabular}

The depositions were made in the ratio of 4 to 1 based on the $80 \mathrm{wt} . \%$ for titanium alloy (Ti6Al4V) and $20 \mathrm{wt} . \%$ for boron carbide $\left(\mathrm{B}_{4} \mathrm{C}\right)$ as shown in Table 1 .

The laser powers used were varied between $800 \mathrm{~W}$ and $2400 \mathrm{~W}$ at an interval of $200 \mathrm{~W}$. The scanning speed of $1 \mathrm{~m} / \mathrm{min}$, gas flow rate of $21 / \mathrm{min}$, powder flow rate of $3.2 \mathrm{rpm}$ for Ti6Al4V alloy and $0.2 \mathrm{rpm}$ for $\mathrm{B}_{4} \mathrm{C}$ were kept throughout the experiment. The beam diameter or spot size of $4 \mathrm{~mm}$ was employed to create the melt pool on the substrate. A focal distance of $12 \mathrm{~mm}$ is maintained between the nozzle tip and the substrate. During the laser surface melting process, the powders were dissolved into the melted pool, leading to the alloying of the sample's surface. To protect the melt pool as well as the deposit from oxidation during laser deposition process, argon gas was initiated at a pressure of $2 \mathrm{MPa}$ to provide shielding. Nine single deposits were made on the substrate and labelled from S1 to S9. Samples were cut laterally from the deposit for further characterization.

\subsection{Microstructure}

The laterally cut samples from S1 to S9 were mounted in resin prior to microstructural investigation. The mounted samples were ground, polished, and etched according to the Struers note of standard metallographic preparation of titanium [30]. The etchant was prepared using the Kroll's reagent with $100 \mathrm{ml} \mathrm{H}_{2} \mathrm{O} ; 1 \mathrm{ml}$ to $3 \mathrm{ml} \mathrm{HF}$ and $4 \mathrm{ml}$ to $6 \mathrm{ml}$ 
$\mathrm{HNO}_{3}$. The samples were studied under the Optical Microscope (OM), using the Olympus BX51M and the SEM using the TESCAN instrument with Vega TC software.

\subsection{Microhardness Test}

The microhardness characterization was performed on a digital Vickers hardness tester. The etched samples were polished again for the hardness test. Indentations were carried out according to ASTM E384-11e1 [31], using a load setting of $500 \mathrm{~g}$ and a dwell time of 15 seconds. Ten indentations were taken on the samples laterally and the distance of $10 \mu \mathrm{m}$ between each indentation was taken into consideration.

\subsection{Dry Sliding Wear Test}

The dry sliding wear tests were conducted using ballon-disc tribometer equipment: a Universal Micro Materials Tester (UMT-2) which operates with a linear reciprocating motion drive. The wear tester was produced by the Centre for Tribology (CETR) Incorporated, USA. A tungsten carbide ball of 10 $\mathrm{mm}$ in diameter under the spindle is designed to rub over the surface of the samples to create the wear. A normal load of $25 \mathrm{~N}$ and a constant stroke length of $2 \mathrm{~mm}$ were used. The frequency and the speed of the reciprocating spindle were maintained at $5 \mathrm{~Hz}$ and $5 \mathrm{~mm} / \mathrm{s}$ respectively. Each deposited Ti6Al4V$\mathrm{B}_{4} \mathrm{C}$ sample was affixed to a non-moving table for the sliding operation. This was carried out according to the standard, ASTM G133-05 [32]. Evaluating the wear loss or volume, the measurements from the wear tester as well as the width measurement on the wear track from the SEM are taken into consideration. However, the wear volumes as well as the wear rates of the linearly operated deposited composite under the normal load application and constantly controlled speed were calculated according to Archard's wear model of Eqs. (1) to (3), respectively [33].

$$
\begin{gathered}
h_{f}=R_{f}-\sqrt{R_{f}^{2}-\frac{W^{2}}{4}}, \\
R_{f}=\frac{4 h_{f}^{2}+W^{2}}{8 h_{f}}, \\
V_{f}=L_{s}\left[R_{f}^{2} \arcsin \left(\frac{W}{2 R_{f}}\right)-\frac{W}{2}\left(R_{f}-h_{f}\right)\right]+ \\
+\frac{\pi}{3} h_{f}^{2}\left(3 R_{f}-h_{f}\right),
\end{gathered}
$$

where, $h_{f}=$ wear depth, $R_{f}=$ radius of the two spherical ends, $W=$ width, $V_{f}=$ wear volume, $L_{s}=$ stroke length. The three highlighted equations are used simultaneously for the wear volume calculation.

\section{RESULTS AND DISCUSSION}

\subsection{Microstructural Evaluation}

The microstructural evaluation of the Ti6Al4V alloy substrate and the laser deposited Ti6Al4V$\mathrm{B}_{4} \mathrm{C}$ composites are presented in this section. The microstructure of the substrate is characterized by the lighter structures called the alpha phase ( $\alpha$-phase) and the darker structures called the beta phase ( $\beta$-phase). The micrographs of the laser-deposited Ti6Al4V$\mathrm{B}_{4} \mathrm{C}$ composites are characterized by three different zones: The deposit zone, the fusion zone, and the heat affected zone. Fig. 2 shows the micrographs of samples S4, S5, S6, S7, S8 and S9 deposited with the laser powers of $1400 \mathrm{~W}, 1600 \mathrm{~W}, 1800 \mathrm{~W}, 2000 \mathrm{~W}$, $2200 \mathrm{~W}$ and $2400 \mathrm{~W}$, respectively.

The micrographs of Figs. 2a to c of samples S4 to S6 are characterized by poor bonding which is observed at the right side of the deposit. The regions showing red ellipses were delaminated due to the embedded non-melted $\mathrm{B}_{4} \mathrm{C}$ in those regions. These occur between the deposit zone and the fusion zone at the laser powers of $1400 \mathrm{~W}, 1600 \mathrm{~W}$, and $1800 \mathrm{~W}$. Obviously in the spotted region, larger particle sizes and the higher melting temperature of $\mathrm{B}_{4} \mathrm{C}$ could also create the void at the interface. The entrapped $\mathrm{B}_{4} \mathrm{C}$ were not fully melted before solidification with the laser powers used. A further increase in the laser power gives good laminate as observed in Figs. $2 d$ to f. Significantly, basket wave-like of alpha titanium $(\alpha-\mathrm{Ti})$ lamella and beta phases were formed on the deposited composites. They were found growing epitaxial and elongated towards the fusion zone and the heat-affected zone (HAZ). The HAZ, in contrast, heated up during the deposition process and acts as a heat sink. The energy density of the laser power and the density of the $\mathrm{B}_{4} \mathrm{C}$ powder initiated the elongated grains of the $\alpha$-Ti lamella and the $\beta$-phase respectively. These have made the grains to extend below the fusion zone. The region under the main deposit is known as the laser melt zone, and this increases with greater energy input. However, this has a significant effect on the cooling rate during solidification [34].

Fig. 3 shows the SEM micrographs of sample S8 deposited at a laser power of 2200 W. Fig. $3 b$ shows the enlarged region of the circle in Fig. 3a, and this was observed to be non-melted $\mathrm{B}_{4} \mathrm{C}$. Most of these have 

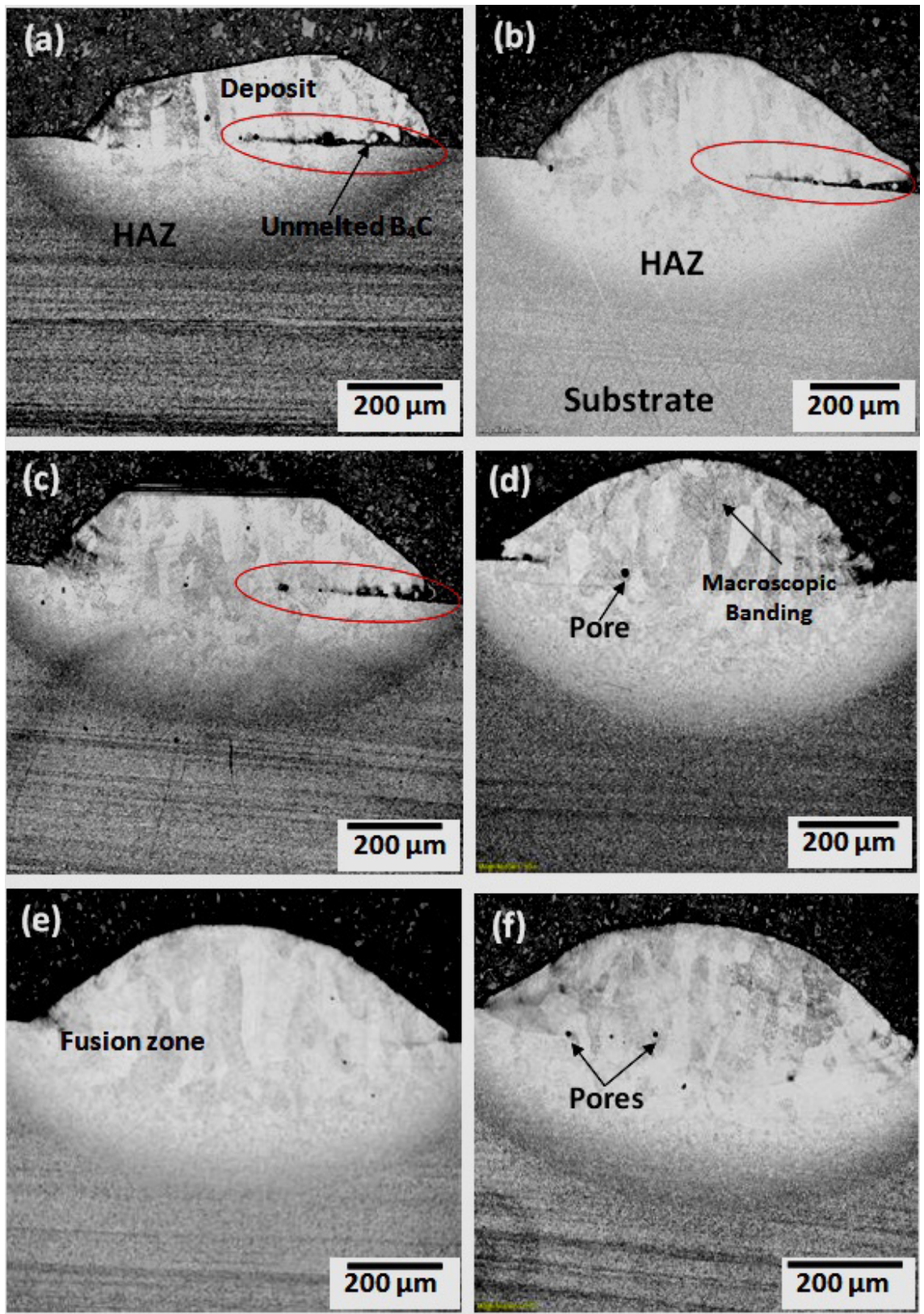

Fig. 2. Micrographs of laser deposited samples S4, S5, S6, S7, S8 and S9 deposited with the laser powers of a) $1400 \mathrm{~W}$, b) $1600 \mathrm{~W}$, c) $1800 \mathrm{~W}$, d) $2000 \mathrm{~W}$, e) $2200 \mathrm{~W}$ and f) $2400 \mathrm{~W}$

created voids in the deposited samples towards the dilution zone. $\mathrm{TiB}$ and $\mathrm{TiB}_{2}$ are very much observed in this region. Moreover, this tends to improve the martensitic phase of the deposit. Macroscopic banding was observed in the deposit of sample S7 deposited with a laser power of $2000 \mathrm{~W}$ and scanning speed of $1.0 \mathrm{~m} / \mathrm{min}$. The $20 \mathrm{wt}$. $\%$ of $\mathrm{B}_{4} \mathrm{C}$ introduced into the deposit has enhanced the properties of the primary alloy. The level of homogeneity occurs at a higher laser power. Thus, this property is characterized by a martensitic microstructure that shows a significant microhardness increase and corrosion resistance improvement [19]. All the samples deposited between the laser powers of $800 \mathrm{~W}$ and $1800 \mathrm{~W}$ were characterized with significance of pores and poor bonding, which is due to the lower laser power used. This behaviour has been traced to the presence of non-melted $\mathrm{B}_{4} \mathrm{C}$ powder that was observed after 


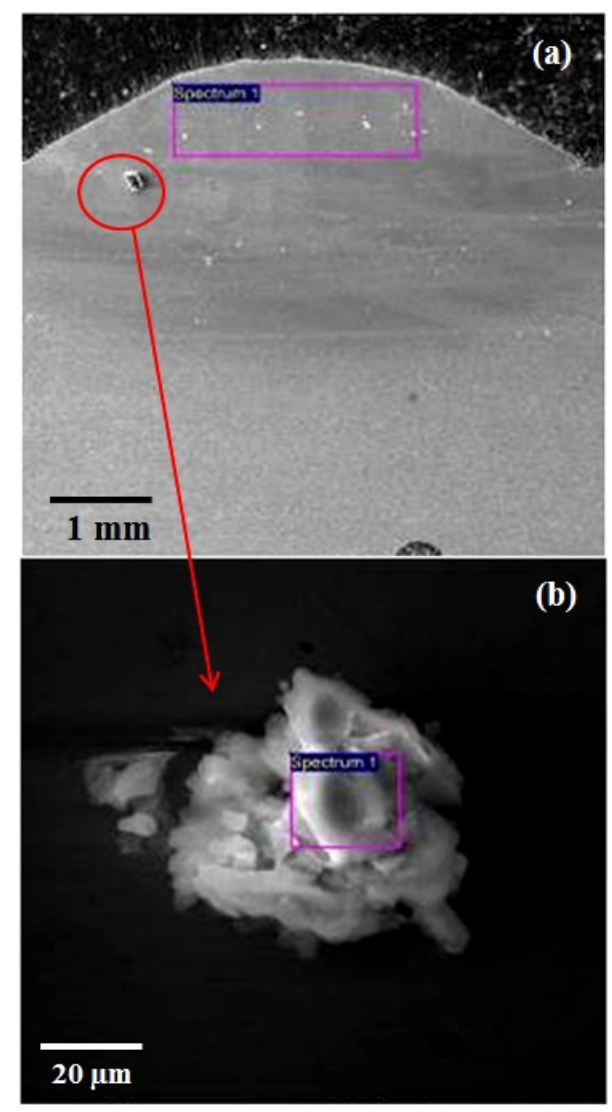

Fig. 3. SEM micrographs of sample S8 deposited at laser power of $2200 \mathrm{~W}$

the solidification of the deposits. Basket weave- $\alpha$ Ti has, however, been known to benefit the mechanical properties of titanium alloy. The deposition width as well as the HAZ width increased as the laser powers was increased. The beam diameter of $4 \mathrm{~mm}$ used has also enhanced the volume of deposited composites.

The EDS analyses were conducted on the defect free composites in order to show the elements that are present in the analysed region. From the spectra observed, titanium exhibits the highest peak. The presence of Aluminium, Vanadium and Carbon was also indicated in the spectra of both samples. The microstructures of the deposited composites were characterized with macroscopic banding, martensitic structures and intermetallic $(\alpha+\beta)$-phase of titanium alloy. Sample S1 to S6 were characterized by a lack -of -fusion and poor bonding, which create a void of nonmelted $\mathrm{B}_{4} \mathrm{C}$ powder after the solidification process and thereby reduces the ductile properties of the grain structures. Samples S7, S8 and S9 deposited at laser powers of $2000 \mathrm{~W}, 2200 \mathrm{~W}$ and $2400 \mathrm{~W}$, respectively, were selected to be the best with elongated columnar grains and Widmanstätten grain structural properties.

The analyses of the x-ray diffraction (XRD) for the laser-deposited composites are presented in the Fig. 4 from samples $S 1$ to $S 3$, respectively.

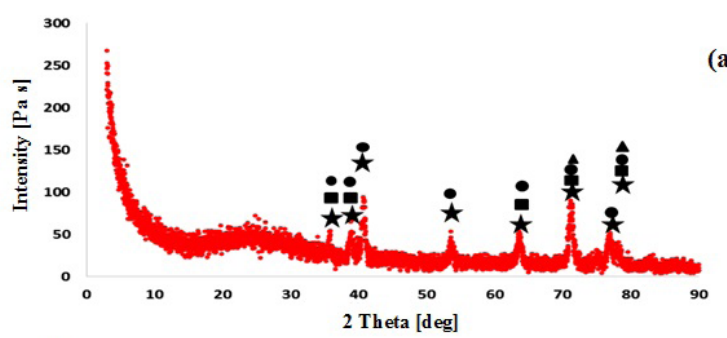

(a)
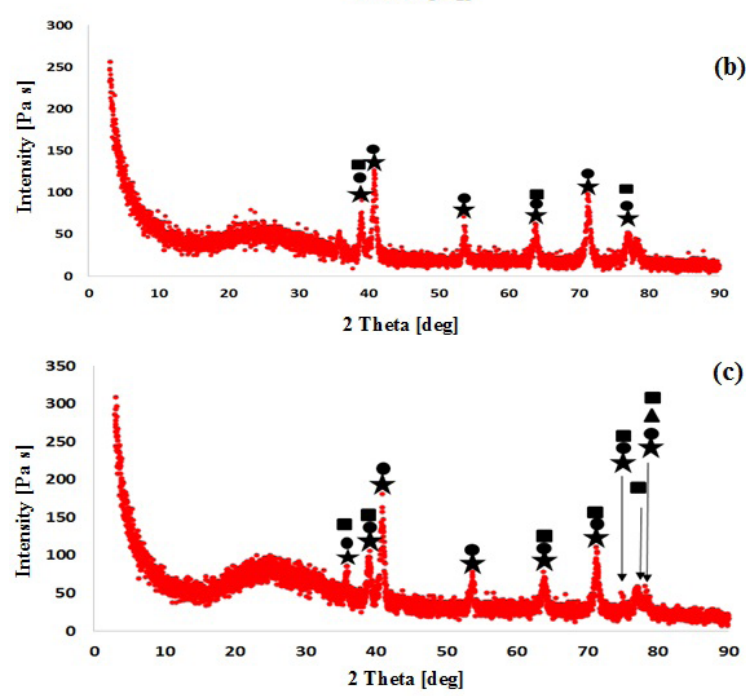

Fig. 4. XRD spectra of the laser deposited Ti6Al4V-B $\mathrm{B}_{4} \mathrm{C}$ composites from samples a) S1, b) S2 and c) S3 and at varying laser power between $800 \mathrm{~W}$ and $1200 \mathrm{~W}$

The XRD patterns presented in Fig. 4 show that the phases were characterized with the increase in the intensity of the diffraction peak patterns of the coatings as the laser power increases. These results, however, suggest that the coatings were composed of slightly low traces of impurities or no irregular impurity of crystalline. Thus, the crystalline phases of the XRD patterns are marked as follow: titanium vanadium carbide, Ti0.33 V1.67 C ( $\star$ ); titanium

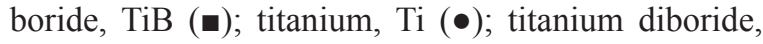
$\mathrm{TiB}_{2}(\boldsymbol{\Delta})$; vanadium carbide, $\mathrm{V}_{2} \mathrm{C}(\boldsymbol{\nabla})$; aluminium titanium vanadium, Al0.5 Ti0.5 V ( $\nabla)$. From the identified peaks, there was no specific shift in the phases as regards to the increase in the laser powers.

Eqs. (4) to (8) show the balanced chemical equations of titanium and boron carbide.

$$
\mathrm{Ti}+\mathrm{B}_{4} \mathrm{C} \rightarrow \mathrm{TiC}+4 \mathrm{~B},
$$




$$
\begin{gathered}
5 \mathrm{Ti}+\mathrm{B}_{4} \mathrm{C} \rightarrow 4 \mathrm{TiB}+\mathrm{TiC}, \\
3 \mathrm{Ti}+\mathrm{B}_{4} \mathrm{C} \rightarrow 2 \mathrm{TiB}_{2}+\mathrm{TiC}, \\
\mathrm{Ti}+1 /{ }_{2} \mathrm{~B}_{4} \mathrm{C} \rightarrow \mathrm{TiB}_{2}+1 /{ }_{2} \mathrm{C}, \\
\mathrm{Ti}+1 /{ }_{3} \mathrm{~B}_{4} \mathrm{C} \rightarrow 2 / 3 \mathrm{TiB}_{2}+1 / 3{ }_{3} \mathrm{TiC} .
\end{gathered}
$$

However, the possible overall stoichiometric equation between the specific grade 5 of Ti6Al4V alloy and the ceramic, $\mathrm{B}_{4} \mathrm{C}$ used in this experiment is given in Eq. (9):

$$
\begin{aligned}
& 4 \mathrm{Ti6Al}_{4 \mathrm{~V}}+\mathrm{B}_{4} \mathrm{C}_{(\mathrm{s})} \rightarrow 2 \mathrm{TiB}_{2(\mathrm{~s})}+ \\
& +5 \mathrm{~V}_{2} 1 / 5 \mathrm{C}_{(\mathrm{s})}+6 \mathrm{Al}_{4}{ }^{1 / 3} \mathrm{TiV}_{(\mathrm{s})}
\end{aligned}
$$

\subsection{Microhardness Profiling}

The microhardness results of the laser deposited composites from samples $\mathrm{S} 1$ to $\mathrm{S} 9$ are presented in Fig. 5.

Fourteen indentations have been put into consideration from the top of the deposit to the substrate. From the microhardness profiling as indicated, there is an increase in the hardness values (HV) from samples $\mathrm{S} 1$ to $\mathrm{S} 9$ as the laser power increases, and at a certain instance, the hardness values show a decrease as the laser power continues to increase. There is also a rise in the hardness value of sample S7 and falls again at samples S8 and S9. From the plot, sample S1 deposited with a laser power of $800 \mathrm{~W}$ exhibits the lowest hardness value and standard deviation of HV $339 \pm 29$, while sample S7 deposited at a laser power of $2000 \mathrm{~W}$ displays the highest hardness value and standard deviation of HV $445 \pm$ 61. However, samples S7 and S9 show some high values of hardness of between HV 530 and HV 545 in the main deposit, and this can be due to the indentation made on the non-melted $\mathrm{B}_{4} \mathrm{C}$. From all indications, the substrate shows the lowest hardness values which falls below HV $339 \pm 29$. The improvement in the hardness values of the laser-deposited samples can be attributed to the $\mathrm{B}_{4} \mathrm{C}$ added. Thus, the variation in hardness values is set as a criterion to improve the ductility property of the composites. It is, however, observed that, an increase in the laser power leads to an increase the hardness values of the deposits. An increase-decrease-increase phenomenon was achieved from the trend of the hardness plot.

\subsection{Wear characterization}

The SEM images of the worn scar for the respective coatings as shown in Figs. 6 a to e from samples S1 to $\mathrm{S} 6$ at low magnification are presented in this section.

The rubbing together of the tungsten ball against the surface of the laser-deposited samples has initiated the wear scar. The worn surfaces are characterized by severe wear with plough and ridge; and wear debris

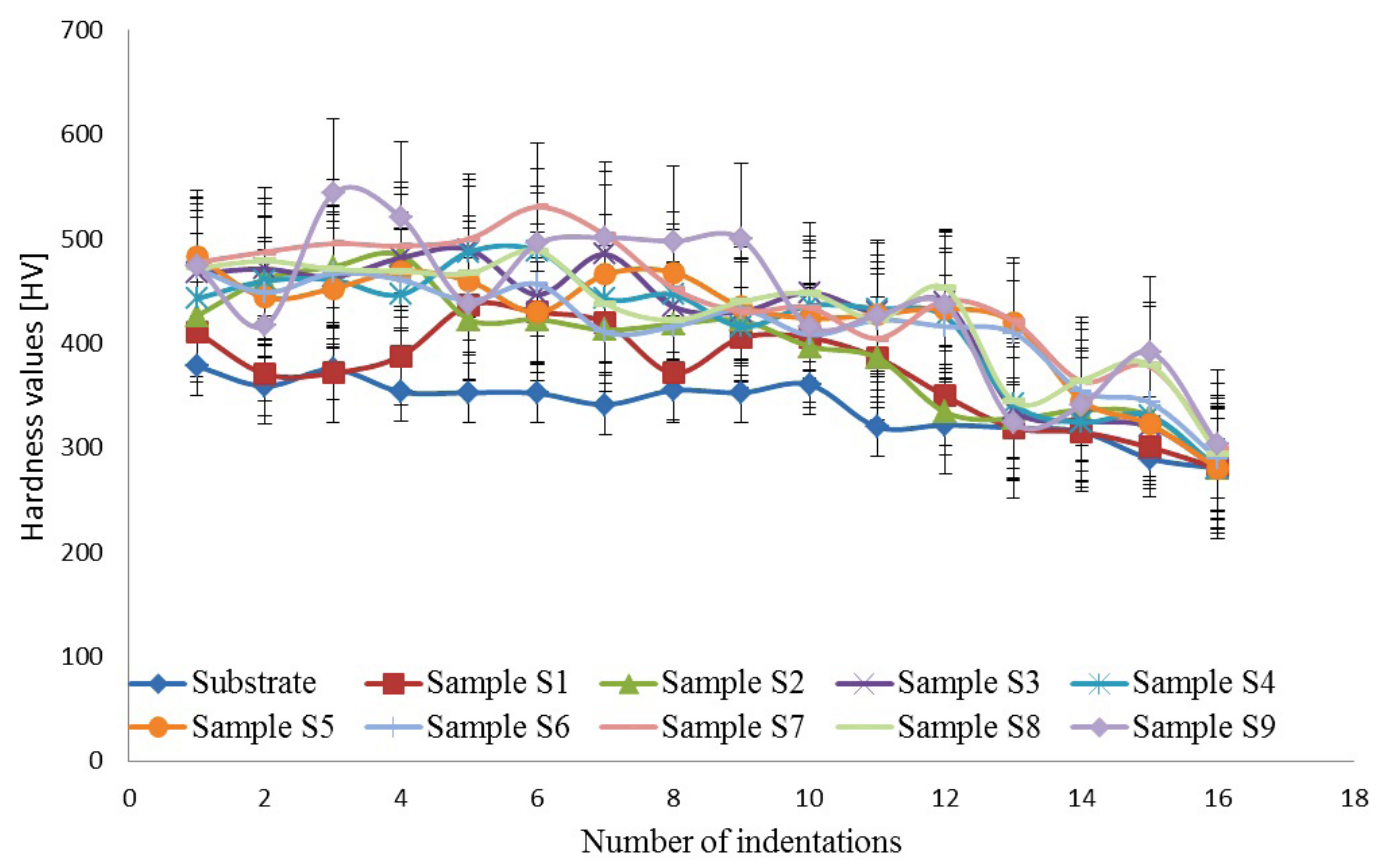

Fig. 5. Microhardness profiling of the laser-deposited Ti6Al4V- $B_{4} C$ composites 
as observed is apparently in all the wear samples. However, the worn surfaces are pronounced by elliptical groove shapes. Samples S1 and S2 deposited with laser powers of $800 \mathrm{~W}$ and $1000 \mathrm{~W}$ show mildly worn surfaces in comparison to other samples. The values of the wear track radius, wear width, stroke length are measured under the SEM in order for the wear volume to be evaluated.

The sliding friction exists between the surfaces of the Ti6Al4V- $\mathrm{B}_{4} \mathrm{C}$ composites and the tungsten carbide ball, which was initiated by the force in action. Wear occurs due to the mechanical action and created an oval shaped groove on the surface of the composites. The wear volume was instigated as a result of the frictional force and the abrasive wear between the tungsten ball and the composite's surfaces. A thicker ridge produced at the plough way shows the extent of the wear volume.

Fig. 7 shows the plots of the wear depth $\left(h_{f}\right)$, wear width $(w)$ and stroke length $\left(L_{s}\right)$ for all the samples, while Fig. 7 shows the histogram plot of the wear volume $\left(V_{f}\right)$ and the wear rate $(K)$.

Figs. 7 and 8 clearly present the plots of the wear depth, the wear width, the stroke length, the wear
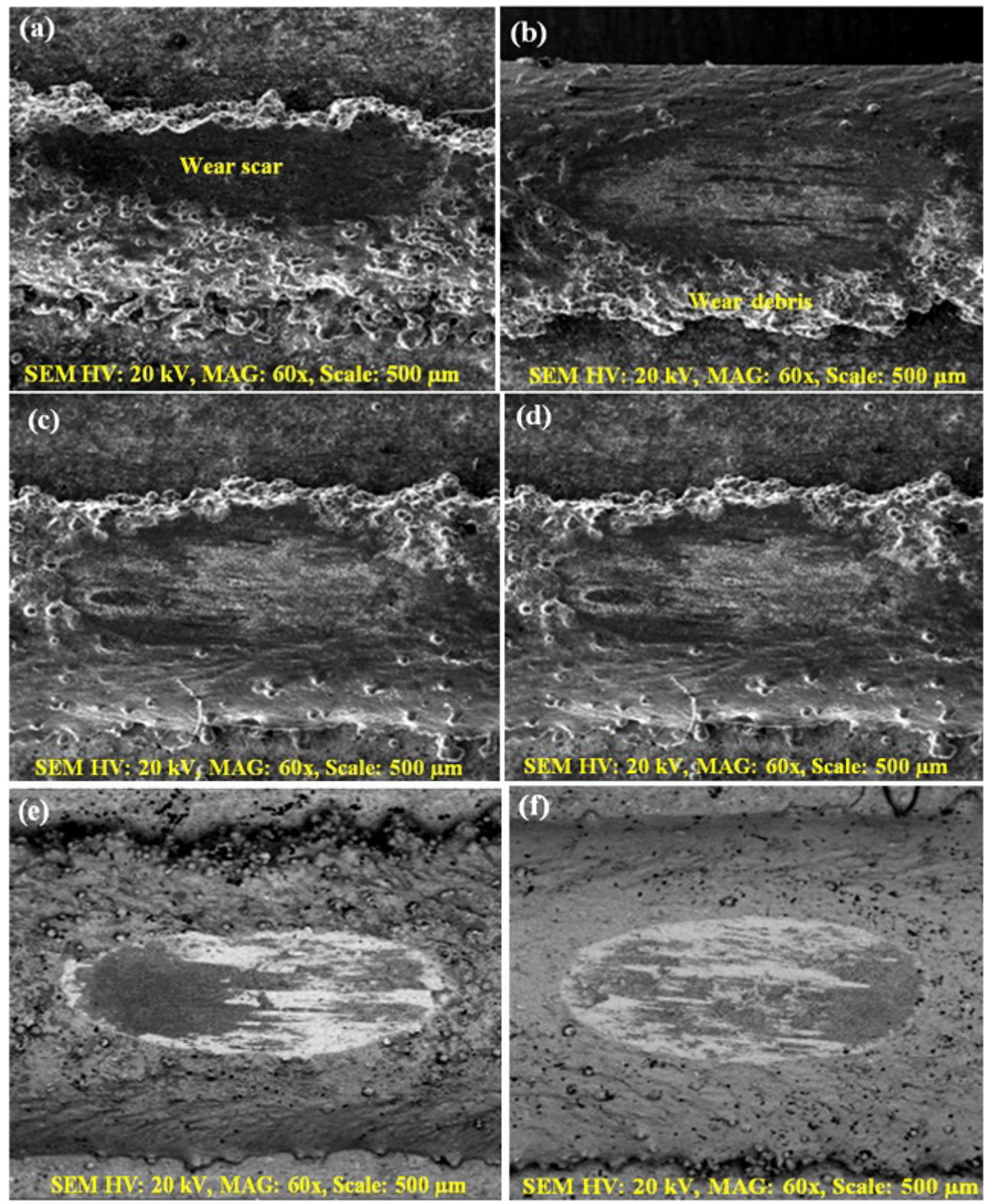

Fig. 6. SEM images of the wear scar on the deposited Ti6AI4V- $B_{4} C$ composites from samples from S1 to S6 


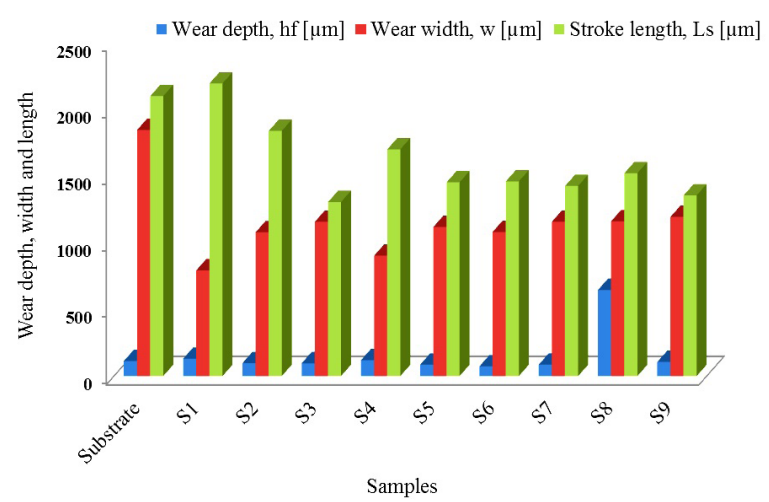

Fig. 7. Plots of the wear depth, wear width and stroke length of the laser-deposited Ti6Al4V- $\mathrm{B}_{4} \mathrm{C}$ composites

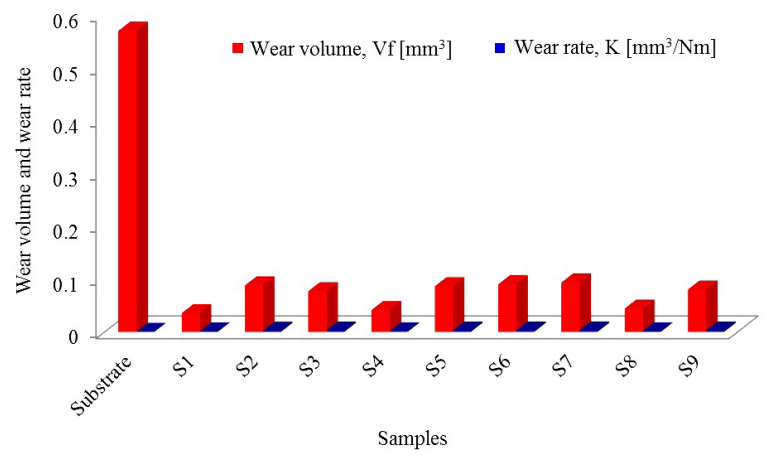

Fig. 8. Graph of the wear volume and wear rate of the laserdeposited Ti6Al4V-B $\mathrm{B}_{4} \mathrm{C}$ composites

volume and the wear rates of all the laser deposited samples. Among the deposited composites, sample S6 deposited at a laser power of $1800 \mathrm{~W}$ has the lowest wear depth with $74.6 \mu \mathrm{m}$ while sample S8 deposited at a laser power of $2200 \mathrm{~W}$ exhibits the highest wear depth with $646.3 \mu \mathrm{m}$. Thus, sample S6 showed profound ductile property than sample S8, which could be due to more heat input associated with the deposition of sample S8 when compared to sample S6. In contrast, more non-melted particles of $\mathrm{B}_{4} \mathrm{C}$ in the melt pool during deposition may have caused the wear depth of sample S6 to have the lowest wear depth value among the rest of the samples. Furthermore, from the histogram chart, both the wear volume and the wear rate were characterized by irregular behaviour, as observed in the trend. From all the deposited composites observed, sample S1 deposited at a laser power of $800 \mathrm{~W}$ has the lowest wear volume and wear rate of $35.2 \times 10^{-3} \mathrm{~mm}^{3}$ and $0.642 \times 10^{-3} \mathrm{~mm}^{3} / \mathrm{Nm}$, while sample S7 deposited at a laser power of $2000 \mathrm{~W}$ possesses the highest wear volume and wear rate of $93.3 \times 10^{-3} \mathrm{~mm}^{3}$ and $2.62 \times 10^{-3} \mathrm{~mm}^{3} / \mathrm{Nm}$, respectively. The depth and width of wear have a significant role to play in determining the wear volume. However, the major role is attributed to the width and length of the wear track. From the histogram plot, the substrate shows the highest wear volume of $569.9 \times 10^{-3} \mathrm{~mm}^{3}$ and the occurrence was as a result of the larger wear width of $1844 \mu \mathrm{m}$ exhibited by the substrate. In other words, all the deposited Ti6Al4V- ${ }_{4} \mathrm{C}$ samples show good wear volume results in comparison with the substrate.

\section{CONCLUSIONS}

The improvement in the surface properties of the Ti6Al4V-B $\mathrm{B}_{4} \mathrm{C}$ composites deposited through the LMD process was significantly achieved in this study. The surface effects of varying the laser power on the microstructure, the microhardness, and the wear were extensively studied and concluded as follows:

- From the microstructural analyses, sample S8 deposited with the laser power of $2200 \mathrm{~W}$ and scanning speed of $1 \mathrm{~m} / \mathrm{min}$ revealed a defect-free surface and good intermetallic phase of $(\alpha+\beta)$ alloy with boron carbide $\left(\mathrm{B}_{4} \mathrm{C}\right)$ particulates.

- Fine globular primary alpha and martensite structures changed to thick and coarse structures as the laser power was increased.

- Sample S1 deposited with a laser power of $800 \mathrm{~W}$ exhibited the lowest hardness value and standard deviation of HV $373 \pm 48$ while sample S7 deposited at a laser power of $2000 \mathrm{~W}$ displayed the highest hardness value and standard deviation of HV $445 \pm 61$.

- The XRD patterns of the laser deposited composites revealed the presence of intermetallic compounds of $\mathrm{TiB}$ and $\mathrm{TiB}_{2}$, which were formed at the interface.

- Both wear volume and wear rate for the deposited composites were calculated using the proposed Archard's wear equation. Sample S7 deposited with a laser power of $2000 \mathrm{~W}$ demonstrated the highest wear volume and wear rate of $93.3 \times 10^{-3} \mathrm{~mm}^{3}$ and $2.62 \times 10^{-3} \mathrm{~mm}^{3} / \mathrm{Nm}$. In the same vein, they both experienced irregular increase-decrease-increase phenomenon as the laser power was increased.

Based on the range of experimental matrix or process parameters adopted, this research study has been able to establish the optimized process parameters between the laser power of $2000 \mathrm{~W}$ and $2400 \mathrm{~W}$ due to the defect-free deposition output. However, this research work can be recommended for the industries dealing with aerospace parts and nuclear device applications. 


\section{REFERENCES}

[1] Jimoh, A. (2010). The Particulate-Reinforcement of Titanium Matrix Composites with Borides. PhD Thesis, The Faculty of Engineering and the Built Environment, University of the Witwatersrand, Johannesburg.

[2] Mahamood, R.M., Akinlabi, E.T. (2015). Effect of laser power and powder flow rate on the wear resistance behaviour of laser metal deposited TiC/Ti6Al4V composites. 4th International Conference on Materials Processing and Characterization. Journal of Materials Today, vol. 2, no 4-5, p. 2679-2686, DOI:10.1016/j.matpr.2015.07.233.

[3] Hager, C.H.Jr., Sanders, J.H., Sharma, S. (2008). Unlubricated gross slip fretting wear of metallic plasma-sprayed coatings for Ti6Al4V. Surfaces, Wear, vol. 2653, no. 3-4, p. 439-451, D0I:10.1016/j.wear.2007.11.026.

[4] Lu, Y., Tang, H.B., Fang, Y.L., Liu, D., Wang, H.M. (2012). Microstructure evolution of sub-critical annealed laser deposited Ti6Al4V alloy. Journal of Materials and Design, vol. 37, p. 56-63, D0l:10.1016/j.matdes.2011.12.016.

[5] Akinlabi, E.T., Akinlabi, S.A. (2015) Characterization of Functionally Graded Commercially Pure Titanium (CPTI) and Titanium Carbide (TiC) Powders. Proceedings of the World Congress on Engineering, Vol. II, London.

[6] Mahamood, R.M., Akinlabi, E.T., Shukla, M., Pityana, S. (2014). Characterization of Laser Deposited Ti6A14V/TiC Composite Powders on a Ti6A14V Substrate. Lasers in Engineering. vol. 29, no. 3-4, p. 197-213.

[7] Matilainen, V. (2012). Benchmarking of Laser Additive Manufacturing Process. BSc Thesis. Lappeenranta University of Technology, Faculty of Technology and Metal Technology, Lappeenranta.

[8] Mahamood, R. M., Akinlabi, E.T., Shukla, M., Pityana, S. (2014). Effect of processing parameters on the properties of laser metal deposited Ti6Al4V using design of experiment. IAENG Transactions on Engineering Sciences, p. 331-339, DOI:10.1201/b16763-37.

[9] Mahamood, R.M., Akinlabi, E.T., Shukla, M., Pityana, S. (2013). Material Efficiency of Laser Metal Deposited Ti6Al4V: Effect of Laser Power. Engineering Letters, vol 21, no. 1.

[10] Mahamood, R.M., Akinlabi, E.T., Shukla, M., Pityana, S. (2013). Scanning velocity influence on microstructure, microhardness and wear resistance performance of laser deposited Ti6Al4V/ TiC composite. Materials and Design, vol. 50, p. 656-666, DOI:10.1016/j.matdes.2013.03.049.

[11] Scott, J., Gupta, N., Wember, C., Newsom, S., Wohlers, T., Caffrey, T. (2013). Additive Manufacturing: Status and Opportunities. Science and Technology Policy Institute, Washington D.C.

[12] Toyserkani, E., Khajepour, A. (2006). A mechatronics approach to laser powder deposition process. Mechatronics, vol. 16, no. 10, p. 631-641, D0l:10.1016/j.mechatronics.2006.05.002.

[13] Choe, H., Abkowitz, S., Abkowitz, S.M. (2008). Influence of processing on the mechanical properties of Ti-6Al-4V-based composites reinforced with 7.5 mass $\%$ TiC and 7.5 mass $\%$ W. Materials Transactions, vol. 49, no. 9, p. 2153-2158, DOI:10.2320/matertrans.MER2008049.
[14] Xiang, W., Xuliang, M., Xinlin, L., Lihua, D., Mingjia, W. (2012). Effect of boron addition on microstructure and mechanical properties of TiC/Ti6Al4V composites. Materials \& Design, vol. 36, p. 41-46, D0I:10.1016/j.matdes.2011.10.040.

[15] Dalili, N., Edrisy, A., Farokhzadeh, K., Li, J., Lo, J., Riahi, A.R. (2010). Improving the wear resistance of Ti-6Al-4V/TiC composites through thermal oxidation (T0). Wear, vol. 269, no. 7-8, p. 590-601, D0l:10.1016/j.wear.2010.06.006.

[16] Wang, F., Mei, J., Jiang, H., Wu, X. (2007). Microstructure and processing properties of Laser fabrication of Ti6Al4V/ TiC composites using simultaneous powder and wire feed. Materials Science and Engineering: A, vol. 445-446, p. 461466, D0I:10.1016/J.msea.2006.09.093.

[17] Rastegari, H.A., Asgari, S., Abbasi, S.M. (2011). Producing Ti-6Al-4V/TiC composite with good ductility by vacuum induction melting furnace and hot rolling process. Materials \& Design, vol. 32, no. 10, p. 5010-5014, D0l:10.1016/j. matdes.2011.06.009.

[18] Uhlmann, E., Hollan, R., El Mernissi, A. (2006). Hybrid DryIce Blasting Laser Processing: Nd-YAG-Laser-assisted DryIce Blasting for De-Coating. Strojniški vestnik - Journal of Mechanical Engineering, vol. 52, no. 7-8, p. 458-462.

[19] Weng, F., Chen, C., Yu, H. (2014). Research status of laser cladding on titanium and its alloys: A review. Materials and Design, vol. 58, p. 412-425, D0l:10.1016/j. matdes.2014.01.077.

[20] Grigoriev, S.N., Tarasova, T.V., Gvozdeva1, G.O., Nowotny, S. (2014). Structure Formation of Hypereutectic Al-Si-Alloys Produced by Laser Surface Treatment. Strojniški vestnik Journal of Mechanical Engineering, vol. 60, no. 6, p. 389-394, DOI:10.5545/sv-jme.2013.1211.

[21] Thévenot, F. (1990). Boron Carbide - A comprehensive review: Journal of the European Ceramic Society, vol. 6, no. 4, p. 205225, D0I:10.1016/0955-2219(90)90048-K.

[22] Levin, L., Frage, N., Dariel, M.P. (2000). A novel approach for the preparation of $\mathrm{B}_{4} \mathrm{C}$-based cermets. International Journal of Refractory Metals and Hard Materials, vol. 18, no. 1-2, p. 131135, D0I:10.1016/S0263-4368(00)00012-3.

[23] Zhang, G.J, Ando, M., Yang, J.F., Ohji, T., Kanzaki, S. (2004). Boron carbide and nitride as reactants for in situ synthesis of boride-containing ceramic composites. Journal of the European Ceramic Society, vol. 24, no. 2, p. 171-178, Dol:10.1016/S0955-2219(03)00607-1.

[24] Dudina, D. V., Hulbert, D. M., Jiang, D., Unuvar, C., Cytron, S.J., Mukherjee, A. K. (2008). In situ boron carbide-titanium diboride composites prepared by mechanical milling and subsequent Spark Plasma Sintering. Journal of Material Science, vol. 43, no. 10, p. 3569-3576, D0l:10.1007/s10853008-2563-8.

[25] Roy, S., Sarkar, A., Suwas, S. (2010). Characterization of deformation microstructure in Boron modified Ti-6Al-4V alloy. Materials Science and Engineering: A, vol. 528, no. 1, p. 449458, D0l:10.1016/J.msea.2010.09.026.

[26] Arrazola, P.J., Garay, A., Iriarte, L.M., Armendia, M., Marya, S., Le Maitre, F. (2009). Machinability of titanium alloys (Ti6Al4V and Ti555.3). A review. Journal of Materials Processing Technology, vol. 209, no. 5, p. 2223-2230, D0l:10.1016/j. jmatprotec.2008.06.020. 
[27] Hadãr, A., Nica, M. N., Constantinescu, I. N, Pastramã, S. D. (2006). The constructive and geometrical optimization of the junctions in structures made from laminated composite materials. Strojniški vestnik - Journal of Mechanical Engineering, vol. 52, no.7-8, p. 546-551.

[28] Tian, Y.S., Chen, C.Z., Chen, L.B., Liu, J.H., Lei, T.Q. (2005). Wear properties of alloyed layers produced by laser surface alloying of pure titanium with $\mathrm{B}_{4} \mathrm{C}$ and $\mathrm{T}\{\mathrm{i}\}$ mixed powders. Journal of Materials Science, vol. 40 p. 4387-4390, D0I:10.1007/s10853-005-0736-2.

[29] Tian, Y.S., Zhang, Q.Y., Wang, D.Y. (2009). Study on the microstructures and properties of the boride layers laser fabricated on Ti-6Al-4V alloy. Journal of Materials Processing Technology, vol. 209, no. 6, p. 2887-2891, D0l:10.1016/j. jmatprotec.2008.06.043.

[30] Struers application Note on titanium. (2015). From http:// www.struers.com/resources/elements/12/104827/
Application_Note_Titanium_English.pdf, accessed on 201515-04.

[31] ASTM E384-11e1. (2011). Standard Test Method for Knoop and Vickers Hardness of Materials. ASTM International West Conshohocken, D0I:10.1520/E0384-11E01.

[32] ASTM Standard G133-05. (2005). Standard Test Method for Linearly Reciprocating Ball-on-Flat Sliding Wear, ASTM International. West Conshohocken, D0l:10.1520/G0133-02.

[33] Shen, X., Cao, L., Li, R. (2010). Numerical simulation of sliding wear based on Archard's model. International Conference on Mechanic Automation and Control Engineering, D0l:10.1109/ MACE.2010.5535855.

[34] Ravnikar, D., Mrvar, P., Medved, J., Grum, J. (2013). Microstructural Analysis of Laser Coated Ceramic Components TiB2 and TiC on Aluminium Alloy EN AW-6082-T651. Strojniški vestnik - Journal of Mechanical Engineering, vol. 59, no. 5, p. 281-290, Dol:10.5545/sv-jme.2012.904. 